Final draft to be submitted to PLOS ONE

\title{
1 Brucella species circulating in wildlife in Serengeti ecosystem,
}

\section{Tanzania}

3 Sambu, R. M. ${ }^{1}$, Mathew C. ${ }^{2}$, Nonga, H.E. ${ }^{2,3}$, Lukambagire A. S. ${ }^{2}$, Richard B. Yapi ${ }^{4,5}$., Fokou

4 G. ${ }^{4}$ Keyyu J. ${ }^{6}$, Bonfoh B. ${ }^{4}$, Kazwala R. R, ${ }^{2}$

$5 \quad{ }^{1}$ Ministry of Livestock and Fisheries, P.O Box 129, Mwanza, Tanzania

$6 \quad{ }^{2}$ College of Veterinary Medicine and Biomedical Sciences, Sokoine University of Agriculture,

7 P. O. Box 3021, Chuo Kikuu, Morogoro, Tanzania.

$8 \quad{ }^{3}$ Ministry of Livestock and Fisheries, P.O Box 2870, Dodoma, Tanzania

$9 \quad{ }^{4}$ Centre Suisse de Recherches Scientifiques en Côte d'Ivoire, Abidjan, Côte d'Ivoire

$10{ }^{5}$ Université Alassane Ouattara, Bouaké, Côte d'Ivoire

$11{ }^{6}$ Tanzania Wildlife Research Institute, Box 661, Arusha - Tanzania 
Final draft to be submitted to PLOS ONE

\section{Abstract}

\section{Background}

14 Brucellosis is a bacterial zoonosis of public health and economic importance world-wide. It affects a number of domestic animals, wildlife and humans. This study was carried out to determine circulating Brucella species in wildlife in Serengeti ecosystem using molecular

17 techniques.

Methodology

A total of 189 samples including EDTA blood, serum and amniotic fluid from buffalos, lions, wildebeest, impala, zebra and hyena that were collected in relation to different cross-sectional studies conducted in the Serengeti ecosystem in Tanzania were used. Multiplex polymerase chain reaction AMOS-PCR and quantitative Real-Time PCR (qPCR) targeting the genus specific surface protein bcsp31 gene and the insertion sequence IS711 element downstream of the alkB gene for B. abortus and BMEI1162 gene for B. melitensis were employed on the samples.

\section{Results}

27 Results indicated that out of 189 samples examined, $12(6.4 \%)$ and $22(11.6 \%)$ contained Brucella DNA as detected by AMOS-PCR and qPCR, respectively. Most of the positive samples were from lions $(52.6 \%)$ and buffaloes (19.6\%). Other animals that were positive

30 included wildebeest, impala, zebra and hyena. Out of 22 positive samples, $16(66.7 \%)$ were

31 identified as B. abortus and the rest were B. melitensis.

\section{Conclusion}

33 Detection of zoonotic Brucella species in wildlife suggests that livestock and humans at the

34 interface areas where there is high interaction are at risk of acquiring the infection. Therefore, public education to interrupt risky transmission practices is needed. The findings also shed light 

perpetuity. It is made available under aCC-BY 4.0 International license.

Final draft to be submitted to PLOS ONE

36 on the transmission dynamics around interface areas and the role of wildlife in transmission

37 and maintenance of Brucella infection in the region.

38 Keywords: Brucellosis, Serengeti, Wildlife, Tanzania 


\section{Introduction}

Brucellosis is a bacterial zoonosis of public health and economic importance world-wide. It affects a number of livestock and wildlife species including humans [1]. The disease is a challenging public health problem to control in many developing countries including Tanzania, especially in pastoral and agro-pastoral farming systems [2-4]. According to WHO, brucellosis is one of the important re-emerging neglected tropical zoonosis [5] largely due to lack of public awareness.

In wild animals, brucellosis can be a result of spill-over from infected livestock or as a natural sustainable infection within susceptible wild animal populations [6,7]. Wild ungulates could acquire infection by ingesting contaminated pasture [7]. Flesh-eaters such as wolves and foxes are thought to be exposed through the ingestion of infected animals, placentae or aborted foetuses [8]. The disease has been reported in wild animals in some African countries, which include Kenya [9], South Africa [7], Zimbabwe [10] and Tanzania [11-14]. In the later country wild animals, Brucella infections have been reported in topi, buffalo, impala, Thompson gazelle and wildebeest $[15,16]$. However, most of these studies have been serology based without indication of circulating Brucella spp. Other studies reported brucellosis in livestock-wildlife interfaces in the Ngorongoro Conservation Area and Mikumi Selous Ecosystem [12-14].

In recent years many African countries have prioritized zoonotic diseases under the global Health Security Agenda. In many countries to date, brucellosis has been ranked among important zoonoses. In Tanzania in particular, it ranks among the top six priority zoonoses that the country will focus control efforts [17]. Since the prioritization of brucellosis in 2017, there have been efforts for development of a control strategy. In implementation of that strategy, critically highlighted areas include the pattern and contribution of different hosts in the transmission and maintenance of brucellosis in the country. Studies have been done on the livestock and shed light 
on Brucella species circulating in different regions of the country [18,19]. However, wildlife transmission dynamics remain a grey area. The aim of this study was to determine circulating Brucella species in wildlife in Serengeti ecosystem in Tanzania, using molecular techniques.

\section{Materials and methods}

\section{Study area}

The study used samples of cross-sectional studies conducted so far in Serengeti ecosystem in Tanzania. The Serengeti is the world's most diverse ecosystem, located in the in north-west of the country between the Ngorongoro highlands and Lake Victoria. This ecosystem comprises of Serengeti National Park, the Ngorongoro Conservation Area, Maswa Game Reserve, Loliondo Game Controlled Area and Kenya's Masai Mara National Reserve (Fig. 1). The study area was selected because there is notable interaction between wild animals, livestock and humans. This area is mainly inhabited by the Maasai with livestock keeping being their main economic activity $[20]$.

\section{$<$ Figure 1 near here $>$}

ecosystem, National Park and the Ngorongoro Conservation Area (expanded insert). Samples used in this study were collected between 2010 and 2017 during routine surveillance and veterinary training programs

\section{Collection of biological samples}

Serum, whole blood and amniotic fluid samples were used in the present study. The samples were collected in connection to other research activities between 2000 and 2017 and archived in the Tanzania Wildlife Research Institute (TAWIRI) biorepository in Arusha, Tanzania and Serengeti laboratory and stored at $-20^{\circ} \mathrm{C}$. The samples were collected from buffaloes, 
wildebeest, zebra, lions, baboon, impala and hyena. In total, 189 samples were collected out of which 11 were amniotic fluid, 170 whole blood and 8 serum samples.

\section{Molecular detection of Brucella spp.}

The study employed AMOS PCR and a quantitative Real-Time PCR (qPCR) in the detection of Brucella spp. from the samples. The PCR protocols used were as described elsewhere [21-23]. In detail, at the Microbiology labs, college of veterinary medicine and biosciences in Sokoine University of Agriculture (SUA) Tanzania, samples were subjected to DNA extraction using a commercial DNA extraction kit (Zymo Research, USA Genomic DNA ${ }^{\text {TM }}$ Tissue Mini Prep kit) and a method as described by Navarro et al. (2002) [24]. Briefly, 40 $\mu 1$ of genomic lysis buffer was added to $200 \mu 1$ of the source sample. The mixture was subjected to digestion, deactivation, washing and elution steps as per manufacturer's instructions. Stock DNA samples were stored at $-20{ }^{\circ} \mathrm{C}$ until the performance of PCR. Primers used in this analysis were obtained from Bioline Inc (Taunton, MA, USA) and are detailed in Table 1.

Table 1: Primers used to amplify the target region of Brucella spp. present in the DNA extracts using the AMOS PCR.

\begin{tabular}{lll}
\hline Primers & Nucleotide sequences 5' to 3' & $\begin{array}{l}\text { Concentration } \\
100 \mathrm{x}(\mu \mathrm{g} / \mu \mathrm{l})\end{array}$ \\
\hline IS711 & TGC-CGA-TCA-CTT-AAG-GGC-CTT-CAT-TGC & 1.90 \\
Abortus & GAC-GAA-CGG-AAT-TTT-TCC-AAT-CCC & 1.55 \\
Melitensis & AAA-TCG-CGT-CCT-TGC-TGG-TCT-GA & 1.48 \\
Ovis & CGG-GTT-CTG-GCA-CCA-TCG-TCG & 1.35 \\
\hline
\end{tabular}


Final draft to be submitted to PLOS ONE

\begin{tabular}{lll}
\hline Suis-biovar 1 & GCG-CGG-TTT-TCT-GAA-GGT-TCA-GG & 1.48 \\
Suis-L & CGA-ACA-CGT-CGG-CAC-GCC-AGT-TCA & 1.60 \\
Suis-R & GCA-TCG-GCG-GGA-AAG-ACA-GCG-TTA-T & 1.60 \\
\hline \multirow{2}{*}{ Primers } & Nucleotide sequences 5' to 3' & \\
& & Concentration \\
& & $100 \mathrm{x}(\mu \mathrm{g} / \mu \mathrm{l})$ \\
\hline IS711 & TGC-CGA-TCA-CTT-AAG-GGC-CTT-CAT-TGC & 1.90 \\
Abortus & GAC-GAA-CGG-AAT-TTT-TCC-AAT-CCC & 1.55 \\
Melitensis & AAA-TCG-CGT-CCT-TGC-TGG-TCT-GA & 1.48 \\
Suis-biovar 1 & GCG-CGG-TTT-TCT-GAA-GGT-TCA-GG & 1.35 \\
Suis-L & CGA-ACA-CGT-CGG-CAC-GCC-AGT-TCA & 1.48 \\
Suis-R & GCA-TCG-GCG-GGA-AAG-ACA-GCG-TTA-T & 1.60 \\
\hline
\end{tabular}

The quantitative qPCR for Brucella spp. identification targeting the bcsp31 gene (GenBank accession number M20404) and IS711 (GenBank accession number HE603358.1) genes were used $[21,23]$. Samples positive for the Brucella genus level target were then subjected to a multiplex assay to distinguish B. abortus from melitensis. The assay used B. abortus and B. melitensis primers targeting the specific insertion of an IS711 element downstream of the alkB (GenBank accession number AF148682) and BMEI1162 (access number NC_003317) genes respectively. Analysis was done according to manufacturer instruction in the Brucella genus Genesig® standard kit (Genesig® Camberly, UK). A volume of $10 \mu 1$ DNA was mixed with primers and probes in $1000 \mu 1$ reaction tubes as described elsewhere [23]. Primers and probes used in the qPCR assay for the detection of Brucella spp. are shown in Table 2. Amplification and real-time fluorescence detection were performed on the iCycler real-time PCR detection system (Bio-Rad Laboratories, 
Hercules, Calif.). Positivity criteria of the assay required that a sample amplifies in both targets and below a set amplification cycle time $(<38)$.

Table 2: Primers and probes used in the real-time multiplex PCR assay for the detection and speciation of Brucella spp.

\begin{tabular}{llll}
\hline PCR ID & Forward primer & Reverse primer & Probe \\
\hline Bcsp31 & ATG-TAT-TGC- & TGC-ATC-AGG- & AAA-TCT-TCC- \\
& GCC-GTC-TGG & CGG-CGA-ATG & $\begin{array}{l}\text { ACC-TTG-CCC- } \\
\text { TTG-CCA-TCA }\end{array}$ \\
& & & CAGGAGTGTTTCG \\
B. melitensis & AACAAGCGGCA & CATGCGCTATGATC & CATCAGAATAATC \\
& CCCCTAAAA & TGGTTACG & GCTCAGA \\
& & & CACA \\
& GCGGCTTTCTA & CATGCGCTATGATC & CGCTCATGCTCGC \\
B. abortus & TCACGGTATTC & TGGTTACG & CAGACTTCAATG \\
& & & \\
\hline
\end{tabular}

The results from each of the techniques were then pooled and cleaned in Microsoft Excel® (IBM, USA v. 2010) then descriptive and crude analytical statistics done using R software (25). Chisquare $\left(\chi^{2}\right)$ or Fisher's exact test were used as appropriate for comparison of; age, sex, location, animal species and Brucella PCR positivity were done. Population differences with a $\mathrm{p}$ value $<$ 0.05 were considered as significant. Cross tabulation was used to determine the diagnostic sensitivity and specificity of the AMOS and real-time qPCR using the qPCR speciation assay as the reference test.

\section{Ethical consideration}

This study was conducted in conformity with the ethical and animal welfare guidelines stipulated by Sokoine University of Agriculture research ethics. A research permit was provided 
by the Tanzania Wildlife Research Institute (TAWIRI) for study conduct in wildlife (TWRI/RS/57/VOL IV/85/72).

\section{Results}

A total of 189 samples from seven wild animal species, (buffaloes, wildebeest, zebra, lions, baboons, impala and hyenas) were used in the present study. Out of these, 170 whole blood collected in the EDTA tubes, 8 sera and 11 amniotic fluid samples.

Most of the samples $(80 ; 42.3 \%)$ were from wildebeest. Most samples $(183 ; 96.8 \%)$ used were obtained from female animals. In terms of specific location, the majority $(115 ; 60.9 \%)$ of the samples were from Serengeti National Park. On crude association with study variables, it was found that the age of the wild animal sampled (Adult), location (Serengeti) and the sample type used for DNA extraction (EDTA whole blood) were all significantly associated with the detection of Brucella DNA (Table 3).

Table 3: Characteristic features of the samples used in the study

\begin{tabular}{lllll}
\hline Variable & Categories & Number $(\%)$ & Pearson's $\boldsymbol{\chi}^{\mathbf{2}}$ & p-value \\
\hline Sex & Female & $183(96.80)$ & 1.08 & $0.30^{\mathrm{a}}$ \\
& Male & $6(3.20)$ & & \\
Age (group) & Adult & $186(98.41)$ & 4.36 & $\mathbf{0 . 0 4}^{\mathrm{b}}$ \\
& Sub-adult & $3(1.59)$ & & \\
Location & Serengeti & $115(60.85)$ & $0.60^{\mathrm{a}}$ \\
& Ngorongoro & $74(39.15)$ & & \\
Species & Buffalo & $46(24.34)$ & & $\mathbf{0 . 0 0 1}^{\mathrm{b}}$ \\
& Wildebeest & $80(42.33)$ & $23.20^{\mathrm{b}}$ &
\end{tabular}




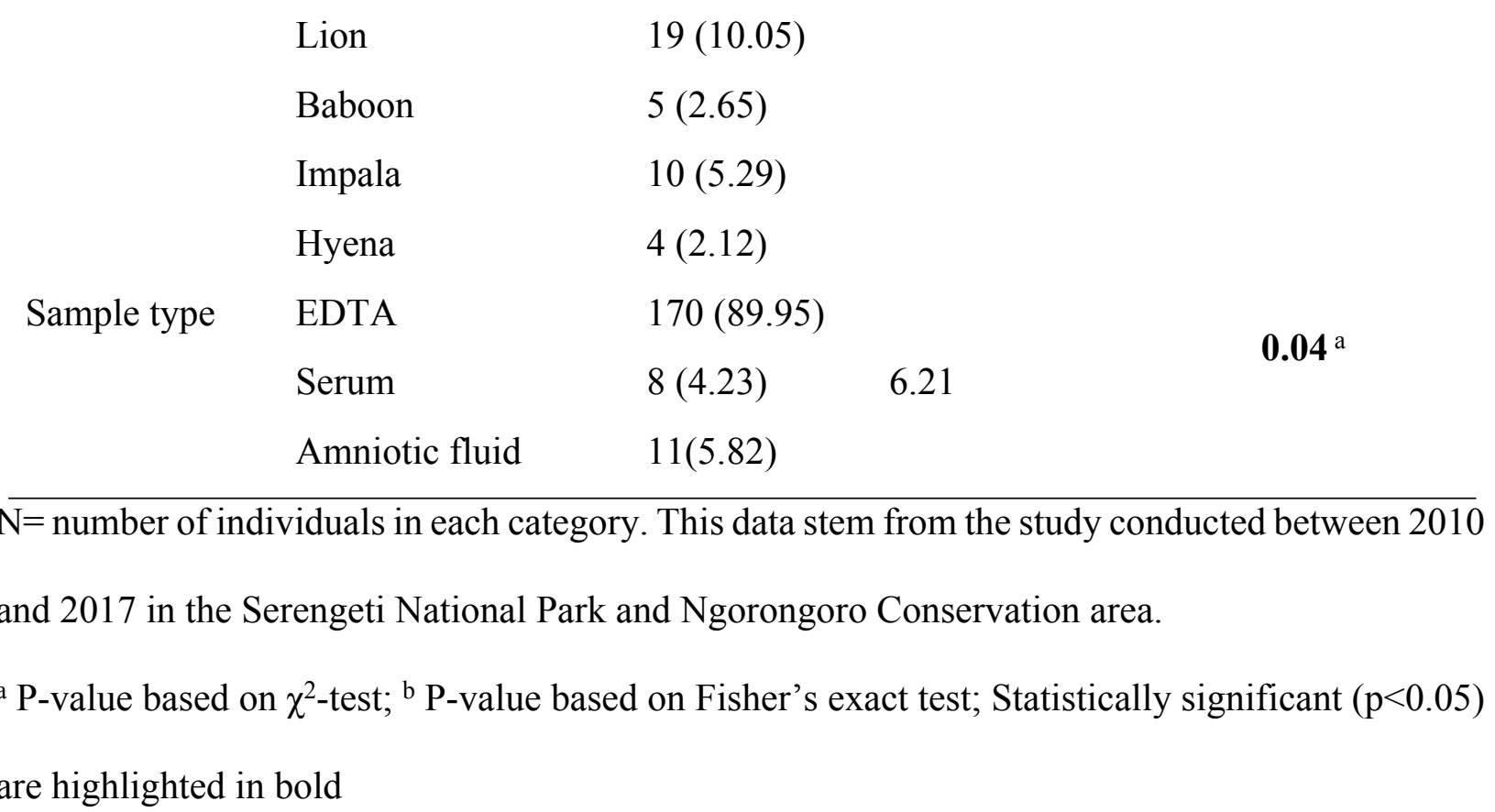

Of the 189 samples screened, Brucella DNA were extracted from $12(6.4 \%)$ samples. Based on AMOS PCR, $16(66.7 \%)$ out of the 24 positive samples were identified as B. abortus, 2 (8\%) were B. suis and $2(8 \%)$ B. melitensis. The animal species distribution of Brucella DNA positive samples based on AMOS PCR are detailed in Table 4. Two samples; from buffalo and impala were found to harbor more than one Brucella species each. The species that were found in a single animal included B. melitensis, $B$. suis and $B$. abortus suggesting multiple infections.

Table 4: Brucella spp. in wild animals in Serengeti ecosystem detected by AMOS-PCR and qPCR $(\mathrm{n}=189)$

\begin{tabular}{lll}
\hline \multicolumn{1}{c}{ Animal spp. } & \multicolumn{1}{c}{ AMOS PCR } & \multicolumn{1}{c}{ q PCR } \\
\hline Lion & Brucella abortus $(\mathrm{n}=3)$ & B. abortus $(\mathrm{n}=6)$ \\
Buffalo & Brucella abortus $(\mathrm{n}=1)$ & B. abortus $(\mathrm{n}=7)$ \\
Wildebeest & Brucella suis $(\mathrm{n}=4)$ & NA \\
Zebra & Brucella suis $(\mathrm{n}=1)$ & B. abortus $(\mathrm{n}=1)$ \\
\hline
\end{tabular}


Final draft to be submitted to PLOS ONE

\begin{tabular}{lll}
\hline Impala & Brucella melitensis $(\mathrm{n}=1)$ & B. abortus $(\mathrm{n}=2)$ \\
Hyena & Brucella suis $(\mathrm{n}=1)$ & NA \\
Baboon & NA & NA
\end{tabular}

$\mathrm{NA}=$ No amplification. This data stem from a study conducted between 2010 and 2017 in the Serengeti National park and The Ngorongoro Conservation area

The qPCR test results indicated that 22 samples (11.6\%) were positive for Brucella DNA. Overall, 16 samples out of $22(66.7 \%)$ samples were positive for $B$. abortus in qPCR. The same 16 samples were also positive for B. abortus in AMOS PCR. Using the real-time speciation assay as the reference test, AMOS PCR had a sensitivity of $16.7 \%$ and specificity of $92 \%$, while the qPCR assay had a sensitivity of $72.7 \%$ and specificity of $100 \%$ (Table 5)

Table 5: Cross tabulation of the molecular tests used, with RT-qPCR speciation assay as the reference

\begin{tabular}{llll}
\hline & Positive & $\begin{array}{c}\text { RT-Speciation } \\
\text { Negative }\end{array}$ & Total \\
\hline $\begin{array}{l}\text { AMOS-PCR } \\
\text { Positive }\end{array}$ & $2(0.167)$ & $10(0.053)$ & $12(0.063)$ \\
$\begin{array}{l}\text { Negative } \\
\text { RT-qPCR }\end{array}$ & $14(0.074)$ & $163(0.921)$ & $173(0.937)$ \\
Positive & $16(0.727)$ & $6(0.032)$ & $22(0.116)$ \\
Negative & $0(0)$ & $167(1.000)$ & $167(0.884)$ \\
Total & $16(0.085)$ & $173(0.915)$ & $189(100)$ \\
\hline
\end{tabular}

\section{Discussion}

Brucella spp. were detected in wildlife in the Serengeti ecosystem. More Brucella spp. DNA were detected in the screened samples using qPCR than AMOS PCR. Lions and buffaloes had the highest proportions of positivity from the sample pool. The most commonly identified species in 
the wild animals was Brucella abortus although B. suis, and B. melitensis were also detected. This is the first reported study to conduct molecular detection of Brucella directly from archived samples.

Results obtained from qPCR show that B. abortus was dominant in the samples collected suggesting that it is a common Brucella species circulating in Serengeti ecosystem. Detection of Brucella spp. from the study area is not surprising as previous studies have reported Brucella seropositivity in wild animals in Tanzania including Serengeti with ranges between $10.5 \%$ and $17 \%$ $[12,15,16,18,25]$. Therefore, detection of pathogenic DNA in samples collected from wildlife in the area confirm that Brucella is circulating in the studied ecosystem.

Most of the Brucella positive samples were detected in female animals 30 (16.4\%) different from the previous report in Tanzania [18] and elsewhere in Africa (3). The current finding further stresses the role of female animals in the transmission and maintenance of Brucella infection. During abortion or normal birth there is massive shedding of Brucellaceae in the environment which are likely to be picked by susceptible animals during grazing [20].

It was further observed that Brucella DNA were detected more in lions (52.6\%) and buffaloes $(19.6 \%)$ than in other wild animal species. The findings could probably be because lions are indiscriminate carnivores and are likely to prey on Brucella infected animals like buffaloes. However, the high detection rates observed in buffaloes may be due to B. abortus being the common species in the ecosystem and is known to mostly infect bovine ungulates. Generally, detection of zoonotic Brucella in wildlife in this study, point to their possible involvement as the source of sustained Brucella transmission in livestock and humans in the interface areas of Serengeti ecosystem. It has been earlier reported that wildlife can act as a source of infection for livestock and humans [25-27]. 
It was also observed that there was higher Brucella infection in Serengeti National Park than in the Ngorongoro Conservation Areas probably because Serengeti is a niche habitat of lions and buffaloes and hence contamination of environment is likely to be high [13]. In addition, in the Ngorongoro conservation area there are close interactions between livestock and wild animals [28]. However, it is unclear whether sustained Brucella infection in wildlife is acquired from livestock or vice versa. Nevertheless, vaccination in livestock may minimize the reverse spread of the disease from livestock to wildlife and vice versa [28].

Wildebeest seasonally migrate from Serengeti to Masai Mara for pastures [29], a practice likely to spread Brucella in the Serengeti ecosystem. Zebra constantly intermingle with wildebeest during grazing [29]; living together in close association and this behavior could be the basis for the transmission of the pathogens amongst the wild animals. Detection of $B$. suis in hyena could be explained by the scavenging behavior in this species.

In this study some animals were detected to have more than one of Brucella spp. B. abortus and B. melitensis, and B. abortus and B. suis were detected in one individual indicating occurrence of multiple infection as it has been reported before [30]. This study also reported the occurrence of B. melitensis and B. abortus in Impala. Studies have associated high sero-prevalences in antelope in Kafue flat area in Zambia because cattle were sharing source of water with wild animals during dry season $[2,27]$. Infection of $B$. melitensis is reported to be less common in sub-Saharan African countries [3133]. Brucella melitensis preferably infect sheep and goat which are related with impala [34].

In this study, qPCR was observed to have a higher detection rate of Brucella spp. than AMOS PCR. This finding is supported by reports from other studies which reported qPCR as superior tool $[21,23,35,36]$. Previous studies that have compared the two platforms and reported similar 
performance in the detection of Brucella DNA [21,36]. This could probably be because AMOS PCR is limited in the detection of all Brucella spp. biotypes. Depending on which biotypes are predominant in the region, example $B$. abortus biovar 3 which has previously been detected in Tanzania [19] cannot be detected in AMOS PCR. Although the assay sensitively detected Brucella DNA in these archived samples, we did not have sufficient quantities and quality to confirm genomic material harvested from such archived samples.

\section{Conclusion}

Findings from this study show that Brucella spp. are circulating in different wildlife spp. in Serengeti ecosystem. The molecular assays run used DNA extracted from archived samples, indicating their potential for routine surveillance of brucellosis on clinical samples. Most of Brucella spp. detected have zoonotic potential. Detection of zoonotic Brucella species in wildlife suggests that livestock and humans at the interface areas are at risk of acquiring the infection. The findings also shed lights on the transmission dynamics around interface areas and the role of wildlife in maintenance and transmission of Brucella infection in the region. The findings from this study, although contextual to the Serengeti ecosystem, provide valuable insights into Brucella infection and host associations in wildlife applicable to much of sub-Saharan Africa

\section{Conflict of interest}

The author declares no conflict of interest. The findings and conclusions in this paper are those of the authors and do not necessarily represent the official position of the participating institutions or the funding organization. 


\section{Acknowledgements}

SRM, CM, AL and RBY acknowledge support from the DELTAS Africa Initiative [Afrique OneASPIRE /DEL-15-008]. Afrique One-ASPIRE is funded by a consortium of donor including the African Academy of Sciences (AAS) Alliance for Accelerating Excellence in Science in Africa (AESA), the New Partnership for Africa's Development Planning and Coordinating (NEPAD) Agency, the Wellcome Trust [107753/A/15/Z] and the UK government.

Laboratory technicians at Sokoine University of Agriculture, and College of Veterinary of Medicine and Biomedical Sciences and Kilimanjaro Clinical Research Institute-Biotechnology Laboratories for technical assistance, Tanzania Wildlife Research Institute (TAWIRI) for their willingness in sharing the samples.

\section{Author contributions}

Concept development; Bonfoh B., Kazwala R. R, Fokou G.

Funding acquisition; Bonfoh B., Kazwala R. R, Fokou G.

Investigation and Formal analysis: Sambu, R. M, Nonga, H.E., Mathew C., Lukambagire A. S., Methodology; Sambu, R. M, Mathew, C., Lukambagire A. S., Richard B. Yapi, Kazwala R. R

Supervision; Nonga, H.E., Mathew C, Keyyu J., Kazwala R. R:

Writing - original draft; Sambu, R. M., Mathew C.

Writing - review \& editing; All Authors 


\section{References}

[1] Pappas G. The changing Brucella ecology: novel reservoirs, new threats. Int J Antimicrob. Agents 2010; 36: 8-11. doi: 10.1016/j.ijantimicag.2010.06.013.

[2] Arimi SM, Koroti E, Kang'ethe EK, Omore AO, McDermott JJ. Risk of infection with Brucella abortus and Escherichia coli $\mathrm{O} 157: \mathrm{H} 7$ associated with marketing of unpasteurized milk in Kenya. Acta Trop, 2005; 96: 1-8, oct. 2005. doi: 10.1016/j.actatropica.2005.05.012.

[3] Mantur BG, Amarnath SK. Brucellosis in India - a review. J Biosci 2008; 539-547. doi:

10.1007/s12038-008-0072-1.

[4] Matope G, Bhebhe E, Muma JB, Oloya J, Madekurozwa RL, Lund A et al. Seroprevalence of brucellosis and its associated risk factors in cattle from smallholder dairy farms in Zimbabwe. Trop Anim Health Prod 2011; 43: 975-982. doi: 10.1007/s11250-011-9794-4.

[5] WHO. Integrated control of neglected zoonotic diseases in Africa: Applying the "One Health" concept. WHO 2009.

[6] Davis DS, Templeton JW, Ficht TA, Williams JD, Kopec JD, Adams LG. Brucella abortus in captive bison. I. serology, bacteriology, pathogenesis, and transmission to cattle. J Wildl Dis 1990; 26: 360-371.doi: 10.7589/0090-3558-26.3.360.

[7] J. A. W. (ed ) Coetzer, G. R. (ed ) Thomson, et R. C. (ed ) Tustin, « Infectious diseases of livestock with special reference to Southern Africa », 1994.

[8] Yingst SL, Huzella LM, Chuvala L, Wolcott M. Rhesus macaque (Macaca mulatta) model of aerosol-exposure brucellosis (Brucella suis): pathology and diagnostic implications. J Med Microbiol, 2010; 59: 724-730. doi: 10.1099/jmm.0.017285-0.

[9] Waghela S et Karstad L. Antibodies to brucella spp. among blue wildebeest and african buffalo in kenya. J Wildl Dis 1986; 22: 189-192. doi: 10.7589/0090-3558-22.2.189.

[10] Madsen M, Anderson C. Serologic Survey of Zimbabwean wildlife for brucellosis. J Zoo

Wildl Med 1995; 26: 240-245.

[11] Hamblin C, Anderson EC, Jago M, Mlengeya T, Hirji K. Antibodies to some pathogenic agents in free-living wild species in Tanzania. Epidemiol Infect 1990; 105: 585-594. doi: $10.1017 / \mathrm{S} 0950268800048226$.

[12] Fyumagwa, RD, Wambura PN, Mellau LSB, Hoare R. Seroprevalence of Brucella abortus in buffaloes and wildebeests in the Serengeti ecosystem: a threat to humans and domestic ruminants. Tanz Vet J 2009; 26: 62-67.

[13] Mellau LSB, Kuya SL, Wambura PN. Seroprevalence of brucellosis in domestic ruminants in livestock-wildlife interface: a case study of Ngorongoro Conservation Area, Arusha, Tanzania. Tanz Vet J 2009; 26: 44-50.

[14] Temba B. Seroprevalence of a Brucella abortus and other Brucella species in wildlifelivestock interface: a case study of Mikumi-Selous Ecosystem. Sokoine University of Agriculture, 2012.

[15] Sachs R, Staak C, Groocock CM. Serological investigation of brucellosis in game animals in Tanzania. Bull Epizoot Dis Afr 1968; 16: 93-100. 
[16] United Republic of Tanzania (URT). National strategy for prevention and control of brucellosis in humans \& animals 2018-2023. Prime Ministers Office 2018.

[17] Assenga JA, Matemba LE, Muller SK, Malakalinga JJ, Kazwala RR. Epidemiology of Brucella infection in the human, livestock and wildlife interface in the Katavi-Rukwa ecosystem, Tanzania. BMC Vet Res 2015; 11: 189. doi: 10.1186/s12917-015-0504-8.

[18] Mathew C, Stokstad M, Johansen TB., Klevar S, Mdegela RH, Mwamengele G, et al. First isolation, identification, phenotypic and genotypic characterization of Brucella abortus biovar 3 from dairy cattle in Tanzania. BMC veterinary research 2015; 11: 156. doi: 10.1186/s12917-015-0476-8.

[19] Probert WS, Schrader KN, Khuong NY, Bystrom SL,. Graves MH. Real-Time Multiplex PCR assay for detection of Brucella spp., B. abortus, and B. melitensis. J Clinl Microbiol 2004; 42: 1290-1293. doi: 10.1128/JCM.42.3.1290-1293.2004.

[20] PINGO's FORUM, CARE International, Tanzania National Resource Forum, Socioeconomic contributions of pastoralism as a livelihood system in Tanzania: case of selected districts in Arusha, Manyara and Dar es Salaam regions. 2016.

[21] Whatmore AM, Perrett LL, MacMillan AP. Characterisation of the genetic diversity of Brucella by multilocus sequencing », BMC Microbiol 2007; 7: 34. doi: 10.1186/1471-21807-34.

[22] Matero P, Hemmilä H, Tomaso H, Piiparinen H, Rantakokko-Jalava K, Nuotio et al. Rapid field detection assays for Bacillus anthracis, Brucella spp., Francisella tularensis and Yersinia pestis. Clin microbiol infect 2011; 17: 34-43. doi: 10.1111/j.14690691.2010.03178.x.

[23] 23. $\mathrm{R}$ Core Team. A Language and environment for statistical computing. http://www.R-project.org, 2018.

[24] Navarro E, Casao MA, Solera J. Diagnosis of human brucellosis using PCR. Expert Rev Mol Diagn 2004; 4: 115-123. doi: 10.1586/14737159.4.1.115.

[25] Mathias LA, Girio RJS, Duarte JMB. Serosurvey for antibodies against Brucella abortus and Leptospira interrogans in pampas deer from Brazil. J Wildl Dis 1999; 35: 112-114. doi: 10.7589/0090-3558-35.1.112.

[26] Godfroid J. Brucellosis in wildlife: -EN- -FR- -ES. Rev Sci Tech OIE 2002; 21: 277-286. août 2002, doi: 10.20506/rst.21.2.1333.

[27] Muma JB, Godfroid J, Samui KL, Skjerve E. The role of Brucella infection in abortions among traditional cattle reared in proximity to wildlife on the Kafue flats of Zambia. RevOff Int Epizoot 2007; 26: 721-730.

[28] Corbel MJ. Brucellosis in humans and animals. WHO Libr Cat Publ Data 2006: 1-88.

[29] McNAUGHTON SJ. Serengeti migratory wildebeest: facilitation of energy flow by grazing. Science 1976; 191: 92-94. doi: 10.1126/science.191.4222.92.

[30] Stoffregen WC, Olsen SC, Wheeler CJ, Bricker BJ, Palmer MV, Jensen AE et al. Diagnostic characterization of a feral swine herd enzootically infected with Brucella. J Vet Diagn Invest 2007; 19: 227-237. doi: 10.1177/104063870701900301.

[31] Gwida M, Al Dahouk S, Melzer F, Rösler U, Neubauer H, Tomaso H. Brucellosis - regionally emerging zoonotic disease?. Croat Med J 2010; 51: 289-295.

[32] Wareth G, Melzer F, Tomaso F, Roesler U, Neubauer H. Detection of Brucella abortus DNA in aborted goats and sheep in Egypt by real-time PCR. BMC Research Notes 2015; 8: 212. doi: 10.1186/s13104-015-1173-1. 
[33] Rajala E. Brucella in Tajikistan-Zoonotic risks of urbanized livestock in a low-income country. Swedish University of Agricultural Sciences 2016: 39-40.

[34] Radostits OM, Gay CC, Hinchcliff KW, Constable PD. A textbook of the disease of cattle, horses, sheep, pigs and goats. Veterinary Medicine, 2007; 10: 2045-2050.

[35] Pérez-Sancho M, García-Seco T, Arrogante L, García N, Martinez I, Diez-Guerrier A et al. Development and evaluation of an IS711-based loop mediated isothermal amplification method (LAMP) for detection of Brucella spp. on clinical samples. Res Vet Sci 2013, 95: 489-494. doi: 10.1016/j.rvsc.2013.05.002.

[36] Doosti, A., Ghasemi Dehkordi P. (2011). Application of real-time PCR for identification and differentiation of Brucella abortus and Brucella melitensis in cattle. Bulgarian Journal of Veterinary Medicine 2011, 14(2), 109-115. 
Figure 1: A map of the study area showing Tanzania conservation areas and the Serengeti ecosystem

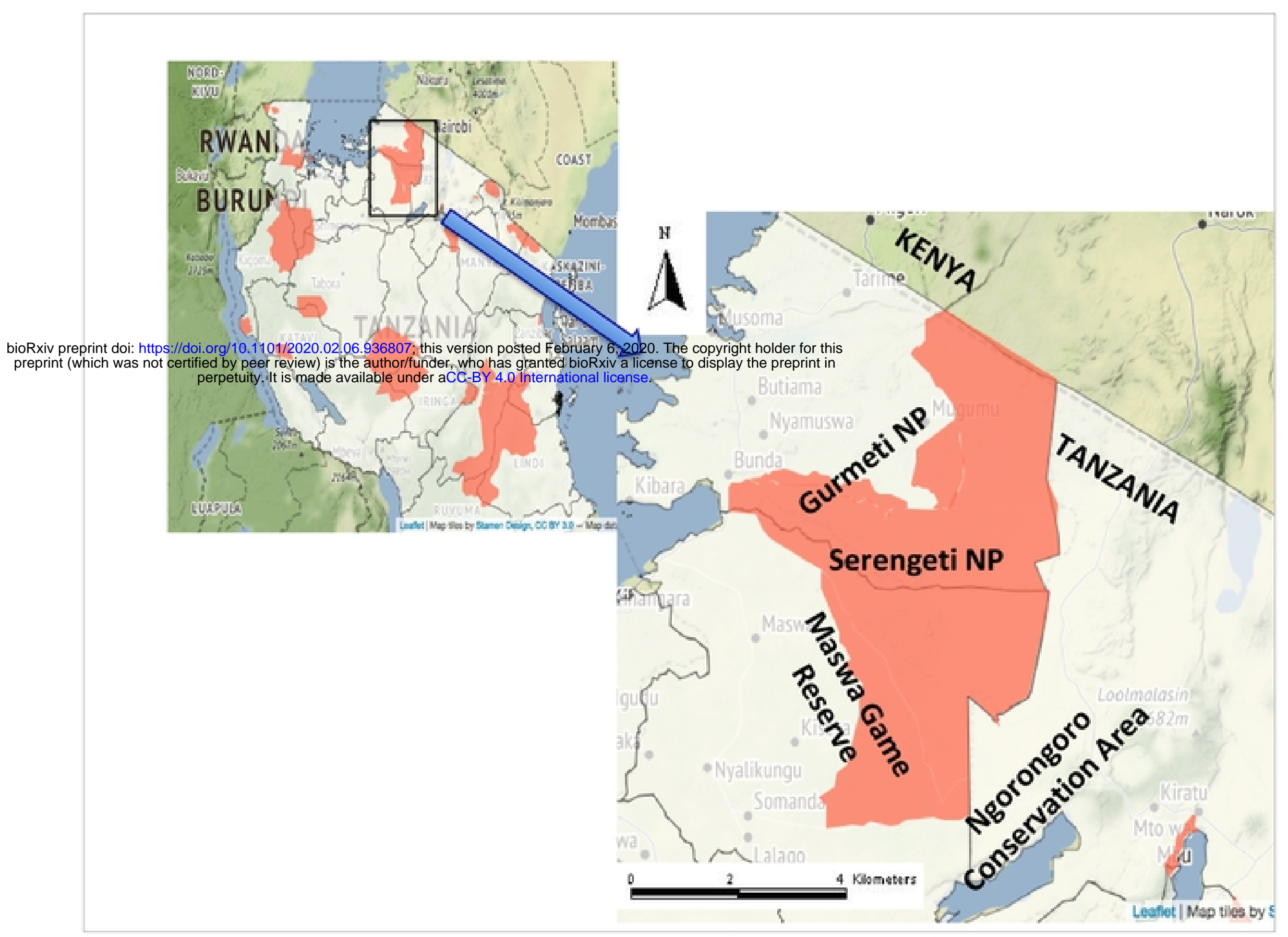

Figure 